\title{
O Conceito De Novas Mídias E A Utilização Das Mídias Na Publicidade ${ }^{1}$
}

\section{The Concept of New Media and the Use of Media in Advertising ${ }^{2}$}

DOI: $10.46814 / \operatorname{lajdv3n4-015}$

Recebimento dos originais: 01/05/2021

Aceitação para publicação: 31/06/2021

\author{
Alessandra Costa Araujo \\ Graduada em Comunicação Social - Publicidade e Propaganda com ênfase em Marketing \\ Coordenadora de Polo na Sustenidos \\ E-mail: alessandracostta@gmail.com
}

\begin{abstract}
André Telles
Estudante de Graduação $7^{\circ}$ semestre do Curso de Publicidade e Propaganda da PUC-Campinas, Trabalho de Iniciação científica com bolsa PIBIC/CNPQ

E-mail: alessandracostta@gmail.com
\end{abstract}

\section{RESUMO}

A propagação da internet e das novas tecnologias trouxe mudanças nas formas de comunicação, assim como do consumo de mídias. Nesse contexto, a mídia social se tornou uma grande ferramenta na vida pessoal e profissional, sendo imprescindível na publicidade. A partir de um levantamento histórico sobre a internet, buscamos fazer um registro, focando o período de 2000 a 2011, para revelar a relação das mídias sociais com a publicidade no Brasil e seu papel de influência nos hábitos e tendências no setor.

Palavras-Chave: Mídias sociais, Mídias digitais, História da internet e publicidade, Comunicação, Publicidade.

\begin{abstract}
The spread of the internet and new technologies has brought about changes in the ways of communication, as well as media consumption. In this context, social media has become a major tool in personal and professional life, being indispensable in advertising. Based on a historical survey of the internet, we seek to make a record, focusing on the period from 2000 to 2011 , to reveal the relationship of social media with advertising in Brazil and its role in influencing habits and trends in the industry.
\end{abstract}

Key Words: Social media, Digital media, History of the internet and advertising, Communication, Advertising.

\footnotetext{
${ }^{1}$ Trabalho apresentado na Divisão Temática de Publicidade e Propaganda, da Intercom Júnior - VI Jornada de Iniciação Científica em Comunicação, evento componente do XXXIV Congresso Brasileiro de Ciências da Comunicação (2011) - sob orientação da Professora Dra. Flailda Brito Garboggini.

${ }^{2}$ Paper presented at the Thematic Advertising Division of Intercom Júnior - VI Journey of Scientific Initiation in Communication, a component event of the XXXIV Brazilian Congress of Communication Sciences (2011) - under the supervision of Professor Flailda Brito Garboggini.
} 


\title{
1 COMUNICAÇÃO DIGITAL: UMA NOVA REALIDADE
}

Com o advento da internet, as distâncias se encurtaram e o mundo ficou mais conectado. As inovações propiciaram uma transformação em larga escala, atingindo a sociedade e também as formas de comunicação, onde velocidade e convergência se tornaram fatores principais nesse novo cenário.

Ao mesmo tempo, as relações sociais (redes) presenciais se transferiram para o mundo virtual, tendo como principal característica reunir e promover a interação de pessoas com interesses e ideologias comuns, modificando as referências de integração.

Para CASTELLS (2009), se trata de um fenômeno pontual e de escala global, que altera a cultura, não somente hoje, mas futuramente: "O surgimento de um novo sistema eletrônico de comunicação caracterizado pelo seu alcance global, integração de todos os meios de comunicação e interatividade potencial está mudando e mudará para sempre nossa cultura" (CASTELLS, 2009, p. 414).

\begin{abstract}
Desde o seu princípio, a Internet é um meio de troca de informações entre pessoas. Assim como existiram vários momentos marcantes na história, podemos afirmar que o surgimento da Internet vem para modificar as relações sociais e marcar definitivamente um novo momento para a humanidade (DOS SANTOS, 2007, p. 20).
\end{abstract}

Isso tudo só foi possível graças às novas formas de acesso à internet que permitiram uma maior inclusão digital no mundo. Impulsionada por questões socioeconômicas, o melhoramento do acesso com a disponibilização da banda larga, wi-fi, além de outras melhorias, mesmo não sendo as ideais, contribuíram na ampliação dessa mídia e na concretização de seu poder de influência e em lançar tendências (mercado). Estas redefiniram o conceito de espectador, agora decisor da grade de conteúdo, personalizando o que se quer ver e quando: "Embora os meios de comunicação realmente tenham se interconectado em todo o globo, e os programas e mensagem circulem na rede global, não estamos vivendo em uma aldeia global, mas em domicílios sob medida, globalmente produzidos e localmente distribuídos" (CASTELLS, 2009, p. 426).

Um outro ponto marcante e que deve ser ressaltado é a descentralização de conteúdos e monopólios que, diferentemente das mídias tradicionais, não se resume em apenas alguns grandes veículos controlando, disponibilizando a informação e cobrindo o território. Há uma maior alternância de domínio, coexistindo com "marcas" que são referências.

A internet deu espaço a quem não tinha ou teria oportunidade nas antigas mídias ou ao que é, de alguma forma, restringido pelas mesmas. Nesse contexto, há a democratização da participação, ou seja, os excluídos dos meios convencionais ganham voz. Pela sua grande variedade de conteúdo, 
coloca a universalidade à disposição de qualquer usuário, se tornando um instrumento de peso na luta de movimentos, minorias e assuntos antes filtrados.

\begin{abstract}
Na mesma linha argumentativa, mulheres e outros grupos sociais oprimidos parecem tender a se expressar de forma mais aberta devido à proteção do meio eletrônico, embora devamos lembrar que, como um todo, as mulheres representavam uma minoria de usuários até 1999. (...) Em razão da novidade histórica do veículo e da relativa melhora do status relativo do poder dos grupos tradicionalmente subordinados, como as mulheres, a CMC poderia oferecer uma oportunidade de reversão dos jogos de poder tradicionais no processo de comunicação (CASTELLS, 2009, p. 446).
\end{abstract}

Diante disso, uma das áreas mais atingidas com essa mudança foi a publicidade, que aos poucos introduziu em sua mecânica de trabalho as novas ferramentas dessa tecnologia, se adaptando a essa nova fase. Assim, paralelamente com a forma tradicional de anunciar, as mídias sociais se tornaram fundamentais para publicidade atingir mais efetivamente os mercados objetivados.

Sem esquecer da efemeridade, pode-se dizer que a instantaneidade recorrente dessa nova mídia, juntamente com a quantidade de informação disponível, promove uma corrida contra o tempo - uma espécie de síndrome de superação -, buscando antever ao que será superado por novas técnicas de comunicação e publicidade, se antecipando ao que amanhã será ultrapassado.

\title{
2 BREVE RESUMO SOBRE A ORIGEM DA INTERNET
}

Inicialmente, inventada para fins militares, a internet por um bom tempo foi restrita ao meio acadêmico, porém isso não impediu que empresas, enxergando uma grande oportunidade, investissem nessa ferramenta a fim de se comunicar e atingir um mercado consumidor extenso.

Foi na tentativa de desenvolver mecanismos de transmissão de dados que a ARPA (Advanced Research Projects Agency) - agência norte americana do Ministério da Defesa, deu os primeiros passos para o que viria a ser a internet. Foi a ARPANET que proliferou em 1982 o IP (Protocolo Internet) usado na comunicação, que teve rapidamente a adesão pelas outras internets no mundo. A que mais se aproxima aos modelos atuais de internet e que ultrapassou o território acadêmico, graças ao investimento do governo americano, foi a NSFnet. Criada em 1981, era totalmente gratuita, exigindo apenas que os interessados tivessem um computador (GEHRINGER; LONDON, 2000, p. 47).

Os investimentos do governo americano com computadores com grande capacidade de tráfego e fundos monetários, além da restrição do uso para fins comerciais, despertou o interesse de empresas em criar uma internet paga, onde os assinantes poderiam, através de vendas online ou anúncios de produtos/serviços, resgatar parte dessa "mensalidade", o que futuramente originaria a 
WWW (World Wide Web) e as empresas online (GEHRINGER; LONDON, 2000, p. 53). "No meio da década de 90, as empresas tradicionais de diversos ramos já tinham seus sites institucionais estruturados na rede e começavam a surgir as novas empresas que, juntamente com as empresas de TI, formariam a chamada 'Nova Economia"' (DOS SANTOS, 2007, p. 28)

\section{CONCEITUAÇÃO DE NOVAS MÍDIAS OU MÍDIAS SOCIAIS}

Quando o assunto é novas mídias ainda existe uma concepção errônea sobre esse termo, muitas vezes servindo de sinônimo para redes sociais. Em A revolução das mídias sociais, TELLES (2010) apresenta essa diferenciação e que é importante conceituar nesse artigo: redes sociais é uma categoria de mídia social (ou novas mídias, como era classificado em 2005). Essas têm como foco reunir pessoas, a relação entre pessoas (membros). Já as mídias sociais englobam diversos sites, desde Twitter, Youtube, Flickr a redes sociais - importante destacar que apesar de alguns definirem Twitter, Youtube e outros como redes sociais, estes não podem ser classificados como tais, pois o seu foco, apesar de permitir essa interação entre os usuários, não é o de ser uma rede social (TELLES, 2010, p. 11).

Ressaltemos que o próprio significado de novas mídias é superado por si só, por estar atrelada a questão temporal. Assim, o termo mídia social se torna mais coerente e amplo quando discutimos sobre as principais mídias popularizadas pela internet, e que de forma geral, não são limitadas pelo tempo em que surgiram.

\section{INTERNET E MÍDIA SOCIAL EM NÚMEROS}

Para dimensionar o cenário da internet e mídias sociais, a Revista Época, em sua publicação online de 20/01/2011, traz números do ano de 2010 sobre essas. São 1,97 bilhões de usuários no mundo, onde a maior concentração está na Ásia, com 825,1 milhões de usuários, seguida de Europa (475,1 milhões), América do Norte (266,2 milhões), América Latina e Caribe (204,7 milhões), África (110,9 milhões), Oriente Médio (63,2 milhões) e Oceania (21,3 milhões).

São 255 milhões de sites (sendo que 21,4 milhões criados só no último ano) e 152 milhões de blogs. Somando os perfis do Facebook (600 milhões) e do Twitter (175 milhões), temos 775 milhões de perfis em apenas duas redes sociais, onde 70\% dos usuários do Facebook estão fora dos Estados Unidos, e 30 bilhões de links, fotos, notas e outros conteúdos são compartilhados por mês nessa rede social. 2 bilhões de vídeos são assistidos por dia no YouTube e 5 bilhões de fotos e outras imagens estão no Flickr, sendo que a cada minuto 3 mil novas imagens são carregadas.

O brasileiro fica em média 8 horas por mês vendo vídeos online, totalizando 86 vídeos por espectador, com duração de 5 a 6 minutos (Uol Tecnologia, 2011), onde 89\% desses assistem 
frequentemente (Meio \& Mensagem, 2011). Também é considerado o país mais sociável do mundo, pois possui 365 amigos virtuais por usuário, onde a média mundial é 195 (FERRARI, 2010).

São 40,53 milhões de internautas brasileiros, um crescimento de $20 \%$ em relação ao ano de 2010, e que gastaram 25,8 horas, acessando 2.077 páginas (Uol Tecnologia, 2011). 80\% desses possuem perfis em redes sociais (FERRARI, 2010), garantindo ao país a $10^{\circ}$ posição na lista dos países que mais acessam essas redes (SA, 2011), onde 42,5\% desses usuários passam cerca de 6 horas conectados - denominados heavy users, sendo mais comuns no Twitter (47\%) e Facebook (48,5\%) (Cultura e Mercado, 2011).

No ranking de tempo gasto em redes sociais, 48,5\% dos usuários do Facebook ficam mais 41 horas por semana conectados nesta rede, no Twitter são 47,2\% que despendem esse mesmo tempo (KNEBEL, 2011). As pessoas passam mais tempo nas redes sociais $(22,7 \%)$ que no e-mail $(8,3 \%)$ quando estão conectadas pelo computador. Quando o acesso é pelo celular, o uso se inverte (Abril.com, 2010).

\section{AS REDES SOCIAIS}

As redes sociais não são tão recentes quanto parecem. Entre as pioneiras estão a Classmates.com e a Sixdegrees, datadas da década de 90. Antes, elaboradas por pessoas com alto nível de conhecimento em tecnologia, eram limitadas pelo número restrito de usuários e poucos recursos de interatividade.

A Classmates.com surgiu em 1995, com o propósito de reunir antigos amigos de colégio e faculdade (DEBIASI, 2011), já a Sixdegrees, criada em 1997, é a que mais se assemelha aos modelos vigentes de redes sociais, caracterizada pelo perfil virtual do usuário e sua lista de amigos (E-dialog, 2011). Porém, por dificuldades financeiras, não conseguiu se manter no mercado.

Essas foram as primeiras das muitas redes sociais que surgiram e que por algum motivo, como não acompanhar a evolução do mercado, se extinguiram. Visualizando o quadro abaixo é possível notar que muitas das redes não obtiveram sucesso logo que criadas, se popularizando apenas anos depois, contudo com o mesmo propósito: “ajudar seus membros a se relacionarem de acordo com interesses comuns e manter contato regular" (DOS SANTOS, 2007, p. 24). 
Classmates.com e Craigslist

Six Degrees.com e AsianAvenue

Care2 e Xanga

LiveJournal e BlackPlanet

MiGente mixi

Cyworld, Ryze, StumbleUpon e

Meetup.com

Friendster, Fotolog, Plaxo e MyLife

Skyblog, Couchsurfing, MySpace,

Tribe.net, Last.FM, Hi5, LinkedIn, Open

BC/Xing, Netlog (Europa) e MyHeritage

Flickr, Piczo, Mixi, Facebook, Dodgeball,

Orkut, Dogster, Multiply, aSmallWorld,

Catster, Hyves, Yelp, Vimeo, Taringa e

Basecamp

Fonte: site Social Media Empresarial

O Orkut ainda é líder no Brasil, com 29,4 milhões de brasileiros participando dessa rede, seguido do Facebook, que encontra-se em expansão e que no último ano contabilizou 8,9 milhões de usuários (YANO, 2010).

$\mathrm{Na}$ lista das mídias sociais mais populares no país em 2010 estão: $1^{\circ} \mathrm{MSN}, 2^{\circ}$ Orkut, $3^{\circ}$ YouTube, $4^{\circ}$ Twitter, $5^{\circ}$ Facebook, $6^{\circ}$ Skype, $7^{\circ}$ FormSpring, $8^{\circ}$ Flickr , $9^{\circ}$ Ning, $10^{\circ}$ Sonico (Blog da Binder Visão Estratégica, 2010). Veja o infográfico da distribuição das principais redes sociais no mundo:

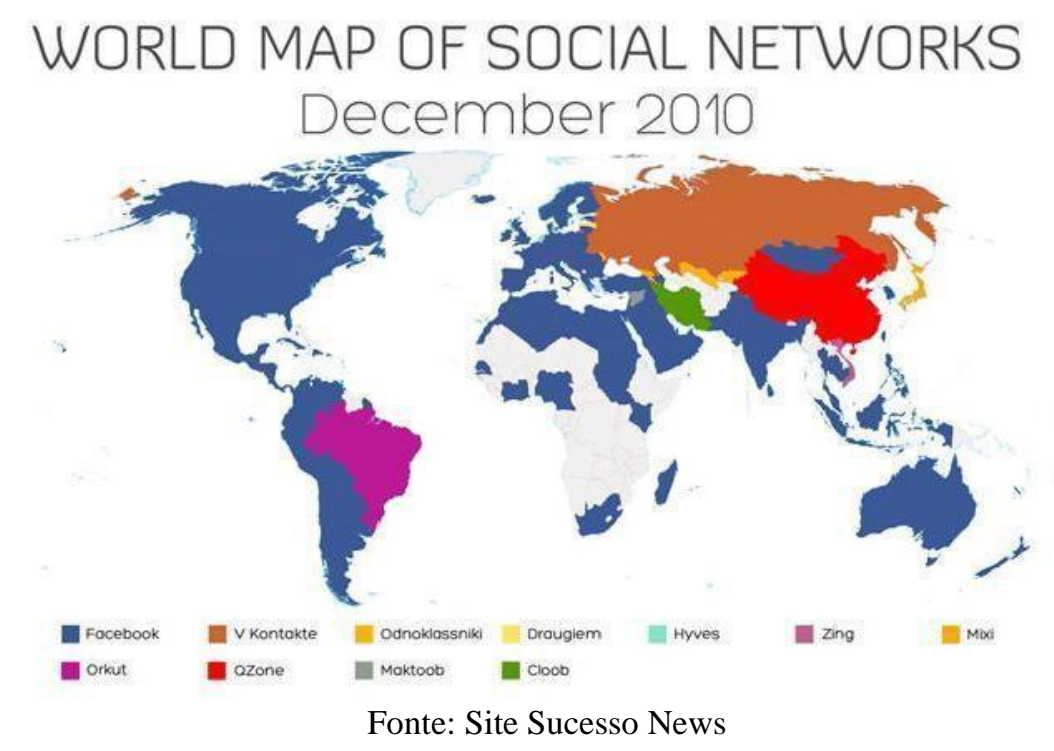


Todos esses dados revelam o vínculo entre as pessoas e a internet e o quanto as redes sociais ganharam espaço, importante, em suas vidas. Observando essa relação e a segmentação proporcionada por essas redes, priorizando interesses específicos de seus usuários (música, futebol, filmes, etc), inevitavelmente se tornou uma grande oportunidade para publicidade, onde o fator de direcionamento atrai e garante um apelo maior junto ao público pretendido.

\subsection{DESTACANDO AS PRINCIPAIS MÍDIAS SOCIAIS: FACEBOOK (FACEBOOK.COM)}

O Facebook foi desenvolvido em 2004 pelo estudante de Havard, Mark Zuckerberg, com intuito de conectar os alunos da universidade através de perfis contendo informações, membros (amigos) e fotos. Tem como característica a interação entre os usuários por mensagens, compartilhamento de fotos, informações, links, vídeos, além do uso de aplicativos como jogos e quiz.

Em pouco tempo ultrapassou o território universitário, possuindo hoje 26,8 milhões de usuários só na Grã-Bretanha. Oficialmente pelo Facebook, são 6 milhões de brasileiros com conta na rede social e recebeu em março de 2011 cerca de 19,04 milhões de visitas do país (SERRANO, 2011). Estima-se que a rede tenha cerca de 700 milhões de usuários ativos no mundo (FLAVIO, 2011).

\subsection{ORKUT (ORKUT.COM)}

Foi criado em 2004 pelo funcionário do Google, Orkut Büyükkokten, e a inscrição na rede social antes era limitada por convites, fazendo dessa muito concorrida em seu início. Em participação mundial de usuários, 50,6\% é constituído pelo Brasil, 20,44\% Índia e 17,78\% Estados Unidos. É o $3^{\circ}$ site mais visitado no país (HAMANN, 2011). Possui funções semelhantes ao Facebook, com variedade menor de aplicativos. Na tentativa de se renovar, já passou por inúmeras atualizações, e em 2011 lançou uma programação ao vivo, trazendo personalidades para serem entrevistadas.

\subsection{TWITTER (TWITTER.COM)}

O Twitter é um microblog que surgiu em 2006 e tem como objetivo compartilhar informações e links em até 140 caracteres. Hoje possui cerca de 200 milhões de usuários no mundo (Terra, 2011). São cerca de 300 mil novos usuários todos os dias (MONTENEGRO, 2010) e o Brasil é o $3^{\circ}$ país que mais "tuíta” (SMAAL, 2010). 


\subsection{YOUTUBE (YOUTUBE.COM)}

Surgiu em São Francisco em 2005, a princípio como um programa para compartilhar vídeos com amigos, desenvolvidos por funcionários da Chad Hurley. Em menos de 2 anos o Youtube foi vendido por US\$1,65 bilhões para o Google $(\mathrm{G1}, 2006)$. Em acessos, o Youtube perde apenas para o buscador do Google e o Facebook e possui 2.159.651 usuários inscritos (LANDIN, 2010).

Depois da transmissão histórica do show ao vivo do U2 em larga escala, com 10 milhões de espectadores no mundo em 2009 (MUSA), o Youtube investiu ainda mais na transmissão de conteúdos ao vivo, antes disponíveis apenas pela televisão ou sites, como a premiação do Grammy, Festival Coachella e a Copa América de 2011.

\subsection{TUMBLR (TUMBLR.COM)}

O Tumblr surgiu em 2007 e seria a junção do Twitter com o Blog. É possível compartilhar imagens, vídeos, links e informações entre os usuários.

A rede social cresceu mais de 5 vezes no último ano, tem 7 milhões de pageviews por mês e 6 milhões de usuários ativos (Pontuaki, 2011), onde seu conteúdo está mais ligado ao entretenimento (HUMBERTO, 2011).

\subsection{MYSPACE (MYSPACE.COM)}

Em 2003 o MySpace apareceu como uma rede social inovadora, além de conectar amigos, também se tornou um espaço para bandas e cantores divulgar vídeos, músicas e compartilhar o seu trabalho.

O caráter multimídia foi o grande diferencial, sendo um espaço online e gratuito que promovia conteúdo musical independente. Atualmente possui 35 milhões de usuários e foi vendido em junho de 2011 por US\$ 35 milhões $(\mathrm{G} 1,2011)$ - já teve 140 milhões de membros em seu ápice (BOTAN, 2009).

\section{RAZÕES QUE LEVAM A USAR AS REDES SOCIAIS}

Sobre as razões que levam os internautas a acessarem as redes sociais, $83 \%$ são questões pessoais e $33 \%$ por questões profissionais. As principais atividades desenvolvidas nessas redes são ver mensagem e navegar (98\%), conversar (76\%) e atualizar o próprio perfil (76\%) (Consumidor Moderno, 2010). Em preferência, 80\% preferem o Orkut e 7\% o Twitter e Facebook, segundo pesquisa da TNS em 2011 (SERRANO, 2011). 


\section{INTERNET E PUBLICIDADE}

A internet revolucionou o mercado das mídias, fazendo com que surgissem agências exclusivas no desenvolvimento de serviços para esse meio. "Um ponto é unanimidade: a publicidade por meio da Internet permite selecionar um público bastante segmentado e interagir com ele" (ABE, 2009).

A primeira vez que a publicidade se juntou com a internet foi em 1994, quando a revista HotWired publicou o primeiro banner em seu site, patrocinado pela AT\&T (MEDEIROS, 2011). Essa revista foi fundamental em trazer a publicidade para a internet, pois através de pequenos anúncios de empresas em seu site, disponibilizou espaço para que a publicidade se inserisse nesse meio, abrindo caminho para que outras revistas, como a Word, também fizessem o mesmo (CANESSO, 2005).

Pode-se dizer que nesse momento, as empresas viram a necessidade de aliar tecnologia (internet) e vendas, ou seja, as novas mídias digitais passaram a ser imprescindíveis para a sobrevivência, onde ser globalizado e conectado se tornou pré-requisito.

Quando as primeiras campanhas publicitárias começaram a ser veiculadas na internet, um dos aspectos mais celebrados pelo mercado, na época, foi a possibilidade de medir em tempo real a quantidade de cliques gerada pela campanha (EGUT, 2008).

Se antes o acesso a internet era limitado pela cobertura, qualidade do serviço ou por ser incipiente ainda, aos poucos, com algumas medidas visionárias, essa revolução passou a atingir um número maior de pessoas. No Brasil, duas empresas foram pioneiras ao lançar a internet gratuita no ano de 2000: BrFree e o IG. Com apenas quatro horas de funcionamento, o provedor IG já tinha 74 mil usuários cadastrados (JIMENEZ; BALARIN; TEIXEIRA; SANTIS, 2000, p. 76).

Segundo Marcelo Sant'Iago em seu Blog, as primeiras agências brasileiras (offline) a usar a internet nos projetos e campanhas foram a J.Walter Thompson, Almap, DM9, DPTO e a Publicis, entre os anos de 1995 e 1996. Por volta de 2000, a JWT passou suas operações de web na América Latina para a agência digital CollectiveMind, trazendo para o país a JWT@Digital. Nessa mesma época, a FNazca também se digitalizou, assim como a Grottera - surgindo a Grottera.com - muitas dessas já não existem ou mudaram de nome. Ainda estão na lista: Euro, McAnn, DPZ, Ogilvy Interactive, AGE, Leo Burnett e entre outras (SANT'IAGO, 2008). Além disso, é possível comparar a relação entre as agências e o mundo digital através da pesquisa do IBOPE de 2008, com as 50 maiores agências de publicidade do Brasil e sua interação com as redes sociais. Podemos citar que entre as 10 principais - 1- Young \& Rubicam: Orkut e Blog; 2- JWT: Orkut; 3- Almap BBDO: Orkut; 4- DM9 DDB: Orkut; 5-McCann Erickson: Orkut e Blog; 6- Ogilvy e Mather Brasil: Orkut; 
7- Africa: Orkut e Blog; 8- Leo Burnett: Orkut; 9- Neogama: Orkut e 10- F/Nazca: Orkut (AMARAL, 2009) - hoje, após três anos, a ligação é maior com o Facebook e o Twitter.

\begin{abstract}
Segundo uma pesquisa realizada através do instituto de pesquisa IBOPE/NETRATINGS o "impacto" da publicidade em redes sociais é 500 vezes maior do que em outras mídias, o que demanda cautela na hora de elaborar a campanha, pois uma rede social é acima de tudo um fator influenciador e seus membros são formadores de opinião (SAYON, 2009).
\end{abstract}

Aos poucos, as mídias sociais adentraram no universo das empresas, sendo essenciais no processo de comunicação dessa, não só pelo seu direcionamento, mas também pelo recall e sua repercussão, maior que das formas tradicionais de propaganda. Dentre as vantagens principais estão o custo, que acaba sendo inferior ao das mídias tradicionais - se pensarmos em um viral ou em mídia espontânea, esse custo se reduz praticamente a zero -; o direcionamento, atingindo o público-alvo; ampla cobertura, ou seja, não há fronteiras que impeçam a mensagem chegar até o "destinatário"; o seu funcionamento ininterrupto, disponível 24 horas; e sem dúvidas, a propagação da mensagem como entretenimento, produzindo assim uma ação menos invasiva ao internauta.

Sobre o entretenimento, a publicidade viu que os anúncios poderiam ser mais que propagandas comuns, revelando-se alternativas diferenciadas para envolver o consumidor, por meio do divertimento:

\footnotetext{
$\mathrm{Na}$ verdade, entretenimento passou a ser um componente importante para atrair o consumo e oportunidades de negócios. Não basta oferecer produtos ou serviços. É preciso informar e divertir (basta olhar as home pages e catálogos das empresas mais descoladas), criar estilos de vida, gerar experiências para as pessoas. (TRIGO, 2003: 145). Outro dado revelado pela pesquisa indica que o uso do entretenimento reforça a presença da marca na mente do consumidor, e se esta

comunicação for feita de forma eficiente pode transformar o próprio usuário em um divulgador da marca através da diversão gerada pela peça (ALBERNAZ, 2009, p. 12).
}

Apesar de todas essas vantagens, o investimento na internet ainda é pequeno no Brasil, mas vem aumentando a cada ano. Nos EUA, por exemplo, a perspectiva era de que em 2010 a verba publicitária online superasse a da mídia impressa (AdNews, 2010). No Reino Unido, em 2009, o investimento publicitário na web já era maior que na tv (QUEIROZ, pág. 38, 2009). Aqui, apenas 4,5\% dessa verba vai para internet, porém estima-se que em 2011 essa cresça 25\%, passando para 6,5\% (Tool Interativa, 2011). Em 2010 os investimentos foram da ordem de R\$ 1,25 bilhões (D'ERCOLE; NOVO, 2011).

Segundo dados do Censo das Agências Digitais de 2010, realizado pela ABRADI (Associação Brasileira das Agências Digitais), são 2.518 agências digitais no país, um crescimento de $10 \%$ em relação ao ano anterior que quantificava 2.275 agências, faturando $\mathrm{R} \$ 974$ milhões. O 
serviço prestado por essas é principalmente na criação de sites e, com grande aumento, em assuntos relacionados às redes sociais e mobile marketing, movimentando cerca de $\mathrm{R} \$ 3$ bilhões com serviços, compra de mídia e Seach Engine Marketing em 2010 (MAFFEIS, 2011). Quanto ao tempo de existência, o Censo de 2009 revela que 43,3\% existe mais de 8 anos e a região sudeste concentra a maior porcentagem de agências digitais, 58,1\% (1.321), seguido do Sul com 15,7\% (357), Nordeste 14,4\% (328), Centro-Oeste 7,7\% (175) e Norte com 4,1\% (94) (Censo das Agências Digitais 2009 ABRADI, 2011).

Atualmente pensar na publicidade sem a internet é praticamente impossível, já que o processo de convergência dos meios está se consolidando a cada dia. Inicialmente usando os banners como forma de publicidade, logo depois os pop-ups, sites e e-mail marketing (HORTINHA, 2000), hoje são inúmeras as ferramentas de vendas, principalmente através das redes sociais e dos advergames (publicidade em jogos) (CRISTINE, 2009). "Repare na importância da integração das mídias sociais: fazem com que o usuário circule pelas mídias sociais com a sua marca, sem interrupção, sem invasão, de forma natural e espontânea. Lembre-se: Mídia Social. Menos mídia, mais social" (TELLES, 2010, p. 43). Em entrevista a revista Próxxima de novembro de 2009, Bartira Pontes, gerente de internet da BorghiErh/Lowe, exemplifica bem o poder das mídias sociais nas empresas: "Pra mim, essa diversidade de ações online, que era tendência, um ensaio em 2008, em 2009 se tornou mandatório. (...) É um movimento que deve incluir o planejamento de comunicação como um todo, trazendo uma nova leitura para o que conhecemos como comunicação 360" (QUEIROZ, 2009, p. 38).

\section{CONCLUSÃO}

Podemos notar que em apenas uma década as transformações trazidas pela internet consolidaram tendências, modificaram a forma de se relacionar das pessoas e exportou novos modelos de comunicação e produção de conteúdo, influenciando até as mídias tradicionais. Estar conectado se tornou indispensável para acompanhar e fazer parte desse universo, permitido, de modo geral, para todos, mas não controlável. A internet não é um fenômeno de caráter apenas tecnológico, mas também sociocultural e comunicacional, atingindo desde o simples usuário à empresa, provocando uma reinvenção constante. E foi nesse processo que a publicidade, identificando uma nova plataforma para seus interesses, se introduziu - em um primeiro momento com a mesma linguagem usada nas mídias de massa, e posteriormente - obedecendo os códigos da grande mídia social. 
A união publicidade e mídia social é recente, mas hoje uma das bases para se fazer propaganda na internet. É fato que a verba destinada para esse meio no Brasil ainda é tímida, mas vem crescendo, mostrando a nova realidade digital: onde os clientes disseminam a marca pelas redes sociais, a substituição ou equiparação dos sites oficiais de muitas agências de publicidade por páginas nessas redes e até mesmo campanhas personalizadas para os seguidores na web.

Portanto, a partir do momento que a internet se popularizou, atingindo as massas, sua relevância se estendeu, colaborando para que as empresas vissem a extrema importância de estar onde o seu consumidor estava. Com a valorização do cliente virtual, a publicidade, nessa adaptação, se duplicou em reconhecimento e representatividade: expandido o real para o virtual. 


\section{REFERÊNCIAS}

ANDERSON, C. Free o futuro dos preços. Rio de Janeiro: Elsevier, 2009.

TELLES, A. A revolução das mídias sociais. M. Books, 2010.

CASTELLS, M. A sociedade em rede. São Paulo: Paz e Terra, 2009.

CASTElo BRAnCO, R.; MARTENSEN, R. L. História da Propaganda no Brasil. São Paulo: T.A. Queiroz, 1990.

GEHRINGER, M.; LONDON, J. O homem no espaço. Odisséia Digital, Abril, p. 43-53 1995, edição especial.

JIMENEZ, Carla; BALARIN, Raquel; TEIXEIRA, Alexandre; SANTIS, Paula. Concorrência Digital. Época, São Paulo, n. 87, p. 76-85, jan 2000.

QUEIROZ, Roberta. O que pegou no universo digital. Próxxima, São Paulo, n. 14, M\&M, nov 2009.

ABE, Maria Carolina: Um novo mundopara a publicidade. Disponível em: <http://administracao.virtual.vilabol.uol.com.br/infoeconomia/artigo10.html>. Acesso em: 10 maio.2009.

Abril.com: Redes sociais são mais populares que e-mail, diz estudo. Disponível em: <http://www.abril.com.br/noticias/tecnologia/redes-sociais-sao-mais-populares-e-mail-diz-estudo583865.shtml>. Acesso em: 10 out. 2010.

ADNEWS: Publicidade na web supera mídia impressa nos EUA. Disponível em: <http://www.adnews.com.br/publicidade.php?id=100415>. Acesso em: 29. set. 2010.

ALBERNAZ, H. Interação e entretenimento na publicidade digital: a visão dos produtores. In: CONGRESSO BRASILEIRO DE CIÊNCIAS DA COMUNICAÇÃO, 32, 2009, Curitiba. Disponível em: <http://www.intercom.org.br/papers/nacionais/2009/resumos/R4-2651-1.pdf>. Acesso em: 20 set. 2010.

AMARAL, Rafael: As 50 maiores agências de publicidade brasileiras e as redes sociais.

Disponível em: <http://www.estagiaridade.com/as-50-maiores-agencias-de-publicidadebrasileiras-e-as-redes-sociais>. Acesso em: 10 maio.2011.

BOTAN, Michele: MY SPACE - Um lugar para amigos. Disponível em: $<$ http://propagandoasredessociais.blogspot.com/2009/12/my-space-um-lugar-para-amigos.html>. Acesso: 10 out. 2010.

Blog da Binder Visão Estratégica: Ranking das redes sociais on-line no Brasil. Disponível em: <http://binderlandia.wordpress.com/2010/07/28/ranking-das-redes-sociais-on-line-no-brasil/>. Acesso em: 20 out. 2010. 
CANESSO, Natacha Stefanini: A Publicidade e a Nova Mídia. Disponível em: <http://blogdomarcuscarvalho.blogspot.com/2005/07/publicidade-e-nova-mdia.html>. Acesso em: 15 jan. 2011.

CHRISTINE, Talita: Publicidade e novas mídias. Disponível em: <http://www.opovo.com.br/www/opovo/economia/848407.html>. Acesso em: 20. agos. 2010.

Cultura e Mercado: $42 \%$ dos brasileiros dedicam seis horas por dia na internet. Disponível em: $<$ http://www.culturaemercado.com.br/noticias/42-dos-brasileiros-dedicam-seis-horas-por-dia-nainternet/>. Acesso: 20 abril. 2011.

DEBIASI, Adam Esteves: Saiba qual foi a primeira Rede Social da Internet. Disponível em: $<$ http://socialmediaempresarial.wordpress.com/2010/04/08/saiba-qual-foi-a-primeira-rede-socialda-internet/>. Acesso em: 15 jan. 2011.

DIAS, Amanda: Infográfico - O domínio das redes sociais no mundo. Disponível em: $<$ http://www.sucessonews.com.br/infografico-o-dominio-das-redes-sociais-no-mundo>. Acesso em: 15 jan. 2011.

DOS SANTOS, Leonardo Borgo Machado. Internet pela ótica das agências de publicidade e propaganda da grande Vitória. 2007. 112f. Dissertação (Monografia em Comunicação Social Habilitação em Publicidade e Propaganda), Departamento de Comunicação Social do Centro de Artes, Universidade Federal do Espírito Santo, Vitória, 2007.

D’ÉRCOLE, Ronaldo; NOVO, Aguinaldo: Publicidade na internet já movimenta R\$ 1,2 bilhão. Disponível em: <http://oglobo.globo.com/tecnologia/mat/2011/02/12/publicidade-na-internet-

ja-movimenta-1-2-bilhao-923791125.asp>. Acesso em: 03 mar. 2011.

EGUT,Katsura Nakamura: Evolução da publicidade online. Disponível em: <http://pavablog.blogspot.com/2008/10/evoluo-da-publicidade-online.html>. Acesso em: 10 out. 2010.

E-dialog: A primeira mídia social. Disponível em: <http://www.edialog.com.br/midia-social/aprimeira-midia-social/>. Acesso: 15 jan. 2011.

FAGUNDES, Renan Dissenha; MICHELSOHN, David: Os números da internet em 2010.

Disponível em: <http://revistaepoca.globo.com/Revista/Epoca/0,,EMI203911-15224,00-OS \%20NUMEROS\%20DA\%20INTERNET\%20EM.html>.Acesso em: 21. jan. 2011.

FERRARI, Bruno: Onde os brasileiros se encontram. Disponivel em: <http://revistaepoca.globo.com/Revista/Epoca/1,,EMI143701-15224,00.html>. Acesso em: 10. out. 2010.

FLAVIO, Lucas: Facebook tem, na verdade, 750 milhões de usuários ativos. Disponível em: $<$ http://www.insidetechno.com/2011/06/23/o-facebook-tem-na-verdade-750-milhoes-de-usuariosativos/>. Acesso em: 19. jun. 2011.

G1.com: Conheça a história do site de vídeos youtube. Disponível em:<http://g1.globo.com/Noticias/Tecnologia/0,,AA1306288-6174,00.html>. Acesso em: 20 out. 2010. 
G1: Rede social MySpace é vendida por 6\% de seu valor há seis anos. Disponivel em: $<$ http://g1.globo.com/tecnologia/noticia/2011/06/rede-social-myspace-e-vendida-por-6-de-seuvalor-ha-seis-anos.html>. Acesso em: 30 jun. 2011.

HAMANN, Renan:O tamanho do Orkut no Brasil. Disponível em: <http://www.tecmundo.com.br/8273-o-tamanho-do-orkut-no-brasil.htm>. Acesso em: 20 maio 2011.

HORTINHA, Joaquim: Os Novos Desafios da Publicidade Interactiva. Disponível em: <http://www.e-marketinglab.com/pub_interact_jnegocios.html>. Acesso em: 20 agos. 2011.

HUMBERTO: O Tumblr no Brasil. Disponível em:

<http://www.agenciadigitown.com.br/2011/04/o-tumblr-no-brasil/>. Acesso em: 04 jun 2011.

KNEBEL, Patricia: Usuários ficam mais tempo nas redes sociais. Disponível em: <http://jcrs.uol.com.br/site/noticia.php?codn=58214>. Acesso em: 05 abril. 2011.

LANDIN, Wikerson: O YouTube em números. Disponível em: <http://www.tecmundo.com.br/ 5810-o-F-em-numeros.htm>. Acesso em: 16 jan. 2011

MAFFEIS, Renata: ABRADi divulga resultados do Censo Digital 2010. Disponível em: <http://

redeabradi.ning.com/profiles/blogs/abradi-divulga-resultados-do-1>. Acesso em: 04 jun. 2011.

MEDEIROS, Rafaela: Publicidade na internet comemora 15 anos. O primeiro banner foi criado pela HotWired. Disponível em: <http://www.almanaquedacomunicacao.com.br/noticias.php?

$\mathrm{id}=142>$. Acesso em: 16 nov. 2010.

Meio \& Mensagem: Vídeos online: a paixão dos brasileiros. Disponível em: <http://www.meioemensagem.com.br/home/midia/noticias/20110624Videos-online-a-paixao-dosbrasileiros.html>. Acesso: 02. junh. 2011.

MONTENEGRO, Chico: Infográfico 1 A história do Twitter e mais algumas revelações.

Disponível em: <http://midiaboom.com.br/2010/05/07/infografico-a-historia-do-twitter-e-maisalgumas-revelacoes/>. Acesso em: 10 out. 2010.

MUSA, Mariana: Show do U2 foi assistido por 10 milhões de pessoas ao vivo pelo YouTube.

Disponível em: <http://www.insidetechno.com/2009/10/29/show-do-u2-foi-assistido-por-10milhoes-de-pessoas-ao-vivo-pelo-youtube/>. Acesso em: 20 out. 2010.

Pontuaki: Tumblr cresce mais de 5x em um ano e já tem 18,8 milhões de blogs cadastrados. Disponível em: <http://pontuaki.com.br/tumblr-cresce-mais-de-5x-em-um-ano-e-ja-tem-188milhoes-de-blogs-cadastrados/>. Acesso em: 04 jun. 2011.

SA, Sylvia: Brasil é o $10^{\circ}$ país que mais acessa redes sociais. Disponível em: <http://www.mundodomarketing.com.br/5,15161,brasil-e-o-10-pais-que-mais-acessa-redessociais.htm>. Acesso em: 20. set. 2010.

SANT'IAGO, Marcelo: Uma breve história das agências de publicidade e a internet. Disponível 
em: <http://marcelosant-iago.com/2008/05/05/uma-breve-historia-das-agencias-de-publicidade-e-ainternet/>. Acesso em: 20 nov. 2011.

SAYON, Daniel. A Evolução das Redes Sociais e a Publicidade. Disponível em: <http://www.mestreseo.com.br/redes-sociais/a-evolucao-das-redes-sociais-e-a-publicidade-2>. Acesso em: 14 setembro. 2010.

SERRANO, Filipe Tavares: Facebook cresce 54\% este ano no Brasil. Disponível em: <http://blogs.estadao.com.br/link/tag/audiencia/>. Acesso em: 20 maio. 2011.

SMALL, Beatriz: A história do Twitter. Disponível em: <http://www.tecmundo.com.br/3667-ahistoria-do-twitter.htm>. Acesso em: 20 maio 2011.

Tool Interativa: Internet deve ter 6,5\% da verba publicitária em 2011. Disponível em: <http://www.toolinterativa.com.br/blog/mercado-e-tendencias/internet-deve-ter-65-da-verbapublicitaria-em-2011/>. Acesso em: 04 jun. 2011.

Uol Tecnologia: Brasileiro gasta em média 8 horas por mês assistindo a vídeos online, indica pesquisa. Disponível: <http://tecnologia.uol.com.br/ultimasnoticias/redacao/2011/05/03/brasileiro-gasta-em-media-8-horas-por-mes-assistindo-a-videosonline-indica-pesquisa.jhtm>. Acesso em: 10. maio. 2011.

Uol Tecnologia: Número de internautas da América Latina cresce 15\%; Brasil lidera tempo de navegação. Disponível: noticias/redacao/2011/03/18/numero-de- internautas-da-america-latina-cresce-15-brasil-lideratempo-de-navegacao.jhtm>. Acesso em: 02. Jun. 2011.

YANO, Celio: Audiência do Facebook cresce $479 \%$ no Brasil em um ano. Disponível em: <http://exame.abril.com.br/tecnologia/noticias/audiencia-facebook-cresce-479-brasil-ano602947>. Acesso em: 16 nov. 2010. 